\title{
Cytomegalovirus retinitis: a manifestation of the acquired immune deficiency syndrome (AIDS)*
}

\author{
ALAN H. FRIEDMAN, ${ }^{1}$ JUAN ORELLANA, ${ }^{12}$ WILLIAM R. FREEMAN ${ }^{3}$ \\ MAURICE H. LUNTZ, ${ }^{2}$ MICHAEL B. STARR, ${ }^{3}$ MICHAEL L. TAPPER,${ }^{4}$ \\ ILYA SPIGLAND,${ }^{5}$ HEIDRUN ROTTERDAM, ${ }^{7}$ RICARDO MESA TEJADA,${ }^{8}$ \\ SUSAN BRAUNHUT,${ }^{8}$ DONNA MILDVAN,${ }^{6}$ AND USHA MATHUR ${ }^{6}$
}

From the ${ }^{2}$ Departments of Ophthalmology and ${ }^{6}$ Medicine (Infectious Disease), Beth Israel Medical Center; ${ }^{3}$ Ophthalmology, ${ }^{4}$ Medicine (Infectious Disease), and ${ }^{7}$ Pathology, Lenox Hill Hospital; 'Ophthalmology, Mount Sinai School of Medicine; ${ }^{5}$ Division of Virology, Montefiore Hospital and Medical Center; and the ${ }^{8}$ Institute for Cancer Research, Columbia University College of Physicians and Surgeons, New York, USA

SUMmary Two homosexual males with the 'gay bowel syndrome' experienced an acute unilateral loss of vision. Both patients had white intraretinal lesions, which became confluent. One of the cases had a depressed cell-mediated immunity; both patients ultimately died after a prolonged illness. In one patient cytomegalovirus was cultured from a vitreous biopsy. Autopsy revealed disseminated cytomegalovirus in both patients. Widespread retinal necrosis was evident, with typical nuclear and cytoplasmic inclusions of cytomegalovirus. Electron microscopy showed herpes virus, while immunoperoxidase techniques showed cytomegalovirus. The altered cell-mediated response present in homosexual patients may be responsible for the clinical syndromes of Kaposi's sarcoma and opportunistic infection by Pneumocystis carinii, herpes simplex, or cytomegalovirus.

Retinal involvement in adult cytomegalic inclusion disease (CID) is usually associated with the concomitant presence of a neoplastic disorder of the haemopoietic and reticuloendothelial systems or treatment with immunosuppressive drugs following allotransplantation. ${ }^{1-3}$ While the diagnosis of CID can often be suggested by the ophthalmoscopic appearance, ${ }^{45}$ confirmation is made by demonstrating the inclusion bodies in urine, saliva, and biopsy specimens, rising serum titres, or positive cultures. ${ }^{6}$ Recently a syndrome has been described involving homosexual males comprising a severe, acquired immunodeficiency and characterised by weight loss, fever, and severe, unrelenting, often fatal infection with opportunistic micro-organisms including cytomegalovirus, herpes simplex virus, Pneumocystis carinii, and Candida albicans. ${ }^{78}$ Other

*Presented at the Eastern Ophthalmic Pathology Society Meeting. Hamilton, Bermuda, 1 October 1981.

Correspondence to Alan H. Friedman, MD. Department of Ophthalmology, Mount Sinai School of Medicine, One Gustave L. Levy Place, New York, NY 10029. USA. manifestations of the syndrome include the 'gay bowel syndrome ${ }^{9}$ and Kaposi's sarcoma. ${ }^{10}$

We herewith describe the ocular findings in 2 previously normal homosexual males who developed a severe immunodeficiency and widespread CID. In one patient cytomegalovirus (CMV) was cultured from the eye ante mortem as well as post mortem, while in the second patient cytomegalovirus was demonstrated in the retina by immunoperoxidase staining post mortem.

\section{Case reports}

CASE 1

The patient, fully reported medically elsewhere, ${ }^{11}$ was a 33-year-old Caucasian exclusively homosexual male who was admitted to Beth Israel Medical Center in September 1980 because of bloody diarrhoea, fever, $40 \mathrm{lb}(18 \mathrm{~kg})$ weight loss, and blurred vision in the left eye in association with significant leucopenia. Examination revealed a wasted male with a temperature of $40^{\circ} \mathrm{C}$, generalised lymphadenopathy, perianal ulcerations, and inflammatory colitis. Oph- 
thalmological examination showed a visual acuity of $20 / 20$ in the right eye and hand motion in the left eye. The intraocular pressure was $14 \mathrm{mmHg}$ bilaterally, by applanation tonometry. The right eye was entirely normal. A marked afferent pupillary defect was present in the left eye. Slit-lamp examination revealed a moderate anterior uveitis in the left eye, manifested by moderate aqueous flare and cells and keratic precipitates on the corneal endothelium. Ophthalmoscopic examination disclosed an oedematous retina with numerous opaque, white intraretinal lesions (Fig. 1). The lesions were elliptically shaped and were orientated towards the optic disc. They were confluent in the macular area, where they appeared brown tinged. Scattered haemorrhages were present in the posterior pole and were noted intermittently to the ora serrata on the temporal side. The optic disc margin was blurred and the disc itself was pale yellow. There was a very mild cellular reaction in the vitreous posteriorly. A fluorescein angiogram in the right eye was unremarkable and in the left eye revealed marked vascular leakage along the superior and inferior temporal arcades and a relative hypofluorescence in the macular area.

Extensive serological testing was nondiagnostic, and multiple cultures, including an aqueous aspirate for bacteria, fungi, and acid-fast bacilli, were negative. Sequential courses of treatment with amphotericin B initiated for oesophageal candidiasis, broad-spectrum antibiotics, and prednisone produced no significant improvement in either the colitis or the retinal lesions. During the fourth week in hospital, when the status of the left eye was noted to deteriorate, a vitreous tap for virus isolation was performed. Cytological examination showed lymphocytes; and 6 weeks later the vitreous material as well as urine yielded cytomegalovirus. The serum complement fixing antibody titre to this virus was repeatedly $1: 128$. During the interval fresh retinal lesions had developed in the previously uninvolved right eye similar to those seen on admission in the left eye. The lesions in the left eye by this time involved large areas of the fundus. The optic disc was markedly pale, the retinal arteries were narrowed and sclerotic, and the retinal veins were sheathed. Diffuse white multifocal retinal opacifications with focal haemorrhages were scattered throughout fundus (Fig. 2). The patient became progressively obtunded, and despite a 10-day course of treatment with intravenous adenine arabinoside (Ara-A), initiated in an effort to treat both the cytomegalovirus retinitis and the perirectal ulcerations from which herpes simplex virus (type II) had been isolated, he lapsed into coma and died approximately 3 months after admission.

General pathology. A general post-mortem examination revealed histologically or by virus isolation disseminated cytomegalic inclusion disease of the lungs, central nervous system, gastrointestinal tract, and liver. Herpes simplex virus was also isolated from these organs.

Ocular pathology. Gross examination: The left eye was obtained for histopathological study and was intact, measuring $25 \times 2 \times 24 \mathrm{~mm}$ with $5 \mathrm{~mm}$ of attached optic nerve. The surface of the globe was unremarkable. The cornea was clear and measured $11 \times 10 \mathrm{~mm}$. Transillumination of the eye revealed some decrease posteriorly. The eye was opened horizontally, showing many white infiltrates in the fundus which were confluent posteriorly (Fig. 3). There were many scattered haemorrhages.

Microscopic examination: The limbal tissues, cornea, and angle were clear. The anterior chamber contained a fibrinous, eosinophilic exudate with erythrocytes and assorted leucocytes. Much of the remainder of the anterior segment was unremarkable except for a mild lymphocytic infiltration in the ciliary body. Posteriorly the retina showed extensive areas of necrosis (Fig. 4). The areas of retinal necrosis were diffuse and full-thickness in many areas. Massively enlarged cells with owl's eye appearance were present (Fig. 5). Scrutiny of cells in the areas of retinal necrosis revealed intracytoplasmic as well as intranuclear inclusions (Fig. 6). The majority of the enlarged cells were in the range $20 \mu \mathrm{m}$ to $30 \mu \mathrm{m}$ in diameter and contained intranuclear basophilic

Fig. 1 Fundus photograph, left eye, case 1. On admission to the hospital several white intraretinal lesions which are confluent in the macular area. There are haemorrhages in the macula. Note overlying vitreous haze.

Fig. 2 Fundus photograph, left eye, case 1. About 4 weeks after admission. The vitreous is slightly hazy, the optic nerve is quite pale, and retinal vessels show narrowing and sclerosis of the arteries and sheathing of the veins. The white lesions have greatly enlarged and become confluent and diffuse.

Fig. 3 Gross photograph of left eye, case 1. The lesions extend from the disc to the periphery and display haemorrhages on a white background. A posterior vitreous aspiration, ante mortem, grew out cytomegalovirus.

Fig. 4 Photomicrograph of left eye, case 1. A prominent area of retinal and retinal pigment epithelial necrosis at right. (Haematoxylin and eosin, $\times 120$ ).

Fig. 5 Higher power view of retina shown in Fig. 4 reveals necrotic retina with haemorrhage, a cell with many cytoplasmic inclusions (lower left), and a markedly enlarged cell, centre. (Haematoxylin and eosin, $\times 1000)$.

Fig. 6 Photomicrograph of necrotic retina shows an enlarged cell with many intracytoplasmic inclusions. (Haematoxylin and eosin, $\times 1800$ ).

Fig. 7 Electron micrograph of the nucleus of a retinal cell demonstrates many viral particles consistent in structure with a herpes family virus. The central capsomer displays the typical hexagonal configuration. $(\times 200000)$. 


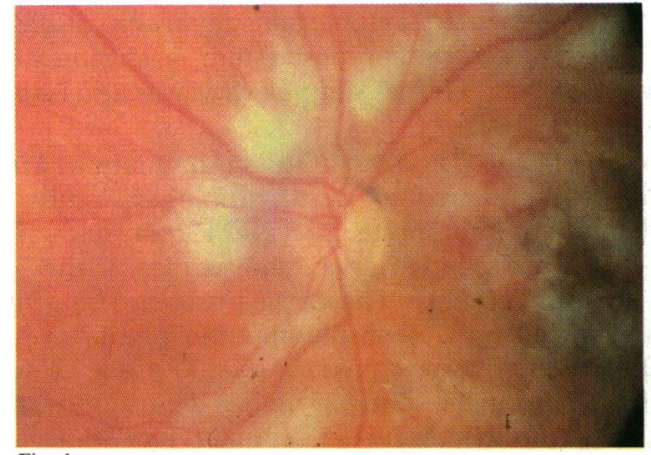

Fig. 1

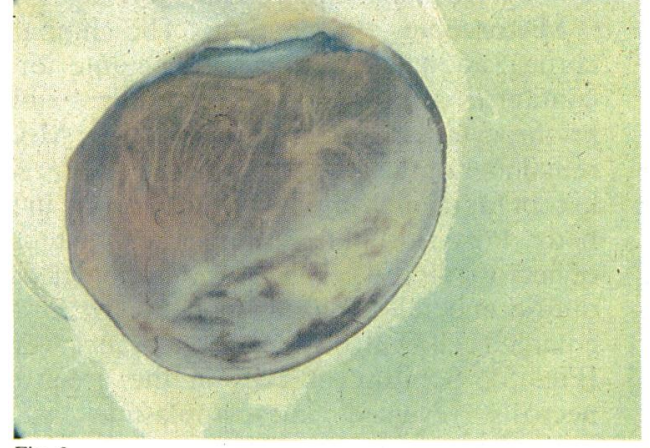

Fig. 3

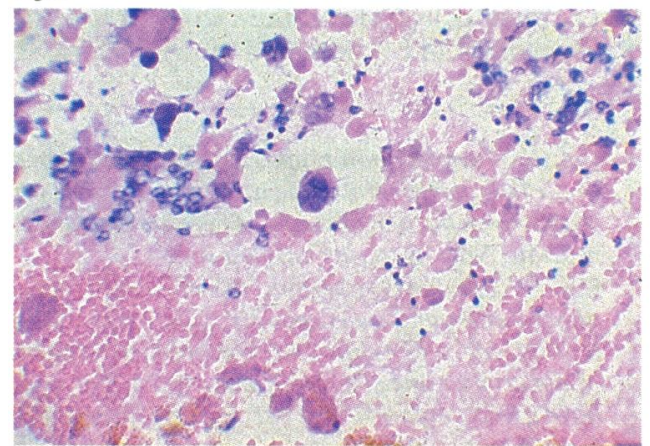

Fig. 5

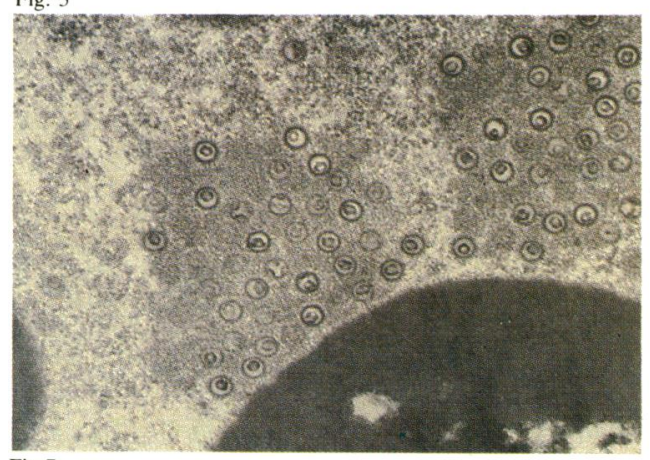

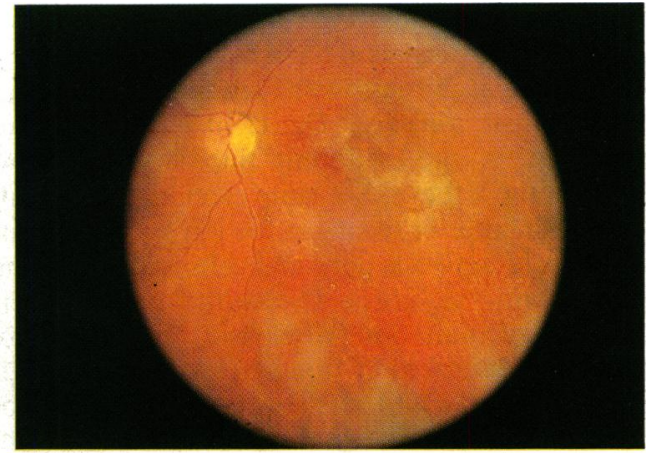

Fig. 2

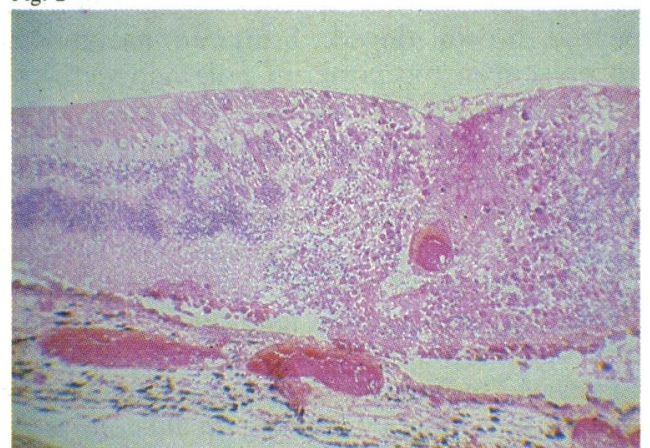

Fig. 4

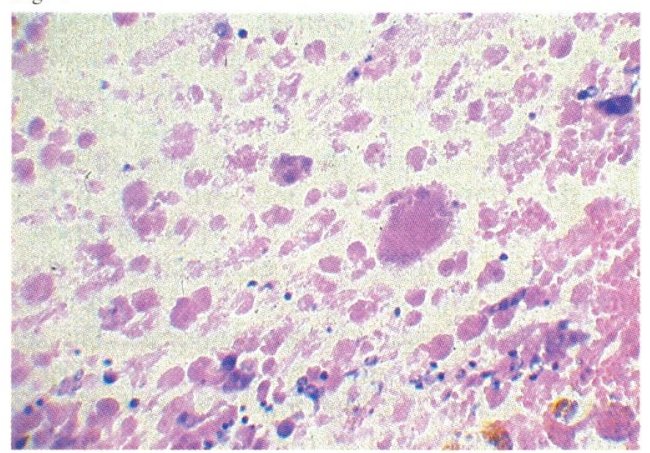

Fig. 6 

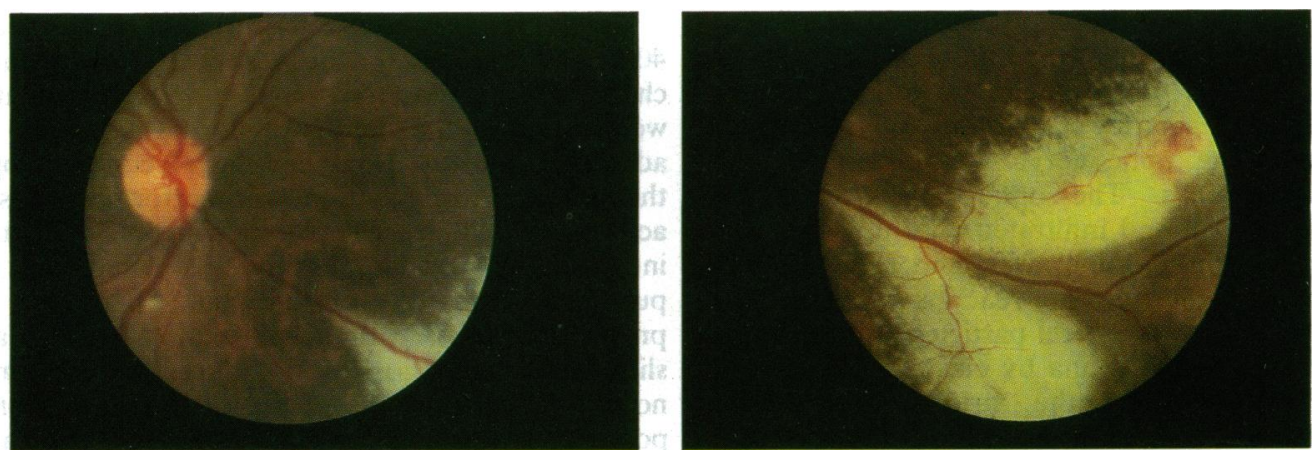

Fig. 8A

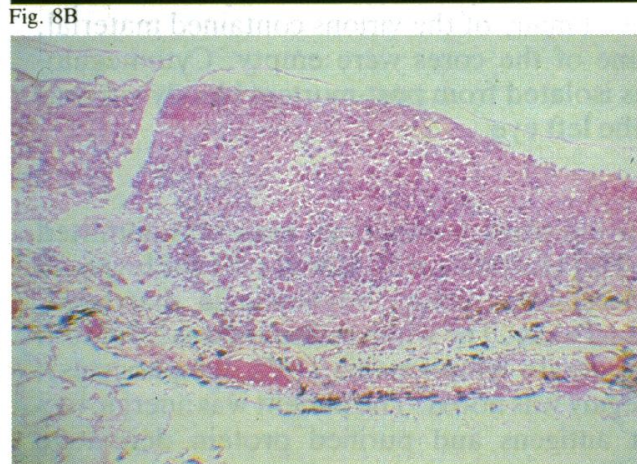

Fig. $8 \mathrm{C}$

Fig. 10

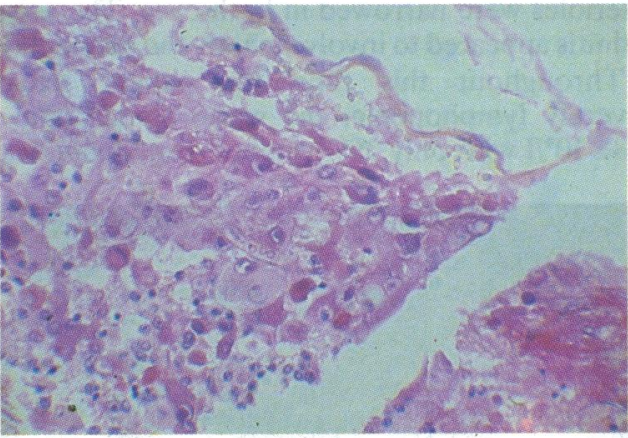

Fig. 11A
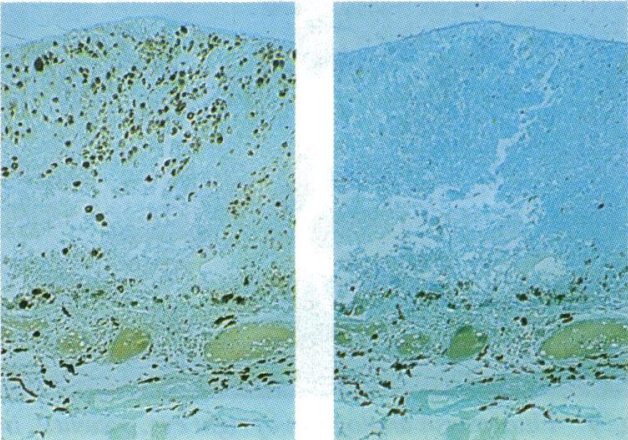

Fig. 12A

Fig. 12B

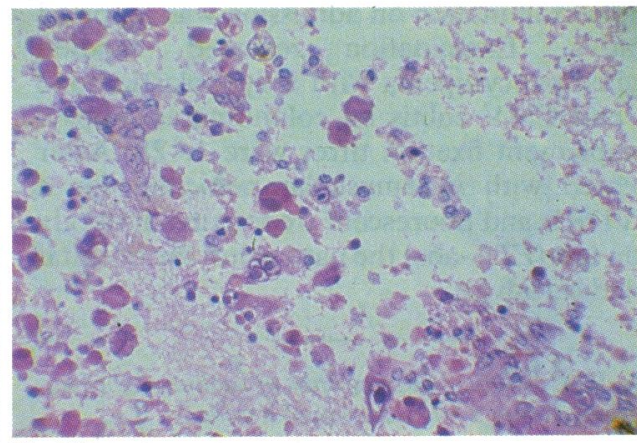

Fig. 11B 
inclusions 5-10 $\mu \mathrm{m}$ in diameter and numerous eosinophilic intracytoplasmic inclusions $0.5-1.0 \mu \mathrm{m}$ in diameter (Fig. 6). Areas of the retinal pigment epithelium were necrotic as well (Fig. 6). The choroid adjacent to the optic nerve was infiltrated with mononuclear cells. The optic nerve head was markedly swollen and infiltrated with inflammatory cells, and the central retinal artery and vein were both occluded. The inflammatory reaction extended into the posterior vitreous. Viral particles (virions) were demonstrated in the retina by electron microscopy (Fig. 7). Structurally the virions contained a hexagonal central capsid surrounded by an envelope. The cores of many of the virions contained material, while some of the cores were empty. Cytomegalovirus was isolated from post-mortem bloody vitreous fluid of the left eye.

\section{CASE 2}

A 38-year-old black homosexual male was admitted to Lenox Hill Hospital on 17 March 1981 for fever, 20 $\mathrm{lb}(9 \mathrm{~kg})$ weight loss, cough, odynophagia, diarrhoea, and perianal ulcer. The white cell count was $2 \cdot 7 \times 10^{9} / 1$ with a moderate lymphopenia ( $15 \%$ lymphocytes); splenomegaly was noted. The patient was anergic to 3 skin test antigens and purified protein derivative (PPD). There were no ocular symptoms and funduscopic examination on admission was reported as negative. Examination revealed candida oesophagitis, pancytopenia with a hypoplastic bone marrow, and CMV colitis by colonoscopic biopsy. CMV complement fixation titres were $1: 128$. After being treated with intramuscular penicillin for a positive VDRL and fluorescent treponema antibody absorption test (FTA-abs) the patient left the hospital against medical advice.

Fig. 8 A, B, C. Clinical photographs of fundus, right eye, patient 2 , reveal large white intraretinal lesions inferotemporal to the macula. Scattered small haemorrhages are present.

Fig. 10 Low-power photomicrograph of retina, case 2, shows extensive area of retinal and retinal pigment epithelial necrosis. (Haematoxylin and eosin, $\times 200$ ).

Fig. 11 A, B. Higher power views of retina shown in Fig. 10. Cells display prominent eosinophilic intracytoplasmic and basophilic intranuclear inclusion bodies. (Haematoxylin and eosin, $\times 1000$ ).

Fig. 12 A, B. Immunoperoxidase localisation of cytomegalovirus proteins in a section of eye (A).

Intracellular brown reaction product is seen in numerous cells in the retinal and pigment layers, many of which lack obvious inclusion bodies. Weak endogenous activity within choroidal vessels is also seen in $\mathrm{B}$, an adjacent section stained with preimmune IgG. Black pigmented epithelial cells and chromatophores are also noted in both sections. (Methylene blue counterstain, $\times 50)$.
He was readmitted one month later with fever of $40^{\circ} \mathrm{C}$ and evidence of dehydration. He appeared chronically ill. Scattered patches of 'soft exudates' were noted in the fundus of the right eye by the admitting internist. Three days later a complete ophthalmological examination was performed. Visual acuity was 20/20 in each eye with a myopic correction in place. Full ocular motility was noted and the pupillary responses were normal. There was no preauricular adenopathy. Applanation tensions and slit-lamp examination of both eyes were entirely normal. There was no evidence of either anterior or posterior vitritis. The fundus of the right eye had a large white retinal infiltrate inferonasally along the distribution of retinal vessels, and intraretinal haemorrhages. A slight disturbance of retinal pigment epithelial was present. The posterior pole showed a few small scattered white retinal lesions $1 / 4$ to $3 / 4$ disc diameter in size and only an occasional small intraretinal haemorrhage (Figs. 8A,B,C). The left eye revealed a few small (less than $1 / 2$ disc diameter) intraretinal infiltrates and occasional haemorrhages in the posterior pole in relation to retinal vessels. Fluorescein angiography showed scattered microaneurysms in both eyes with extensive leakage over the large inferonasal area of retinal involvement OD. (Fig. 9). Several of the retinal arterioles were narrowed in both eyes. The areas of retinitis appeared to involve mainly the deeper layers.

Throughout this time the patient remained severely lymphopenic, the white blood count was $2 \cdot 8 \times 10^{9} / 1$ with only $3 \%$ lymphocytes. Quantification

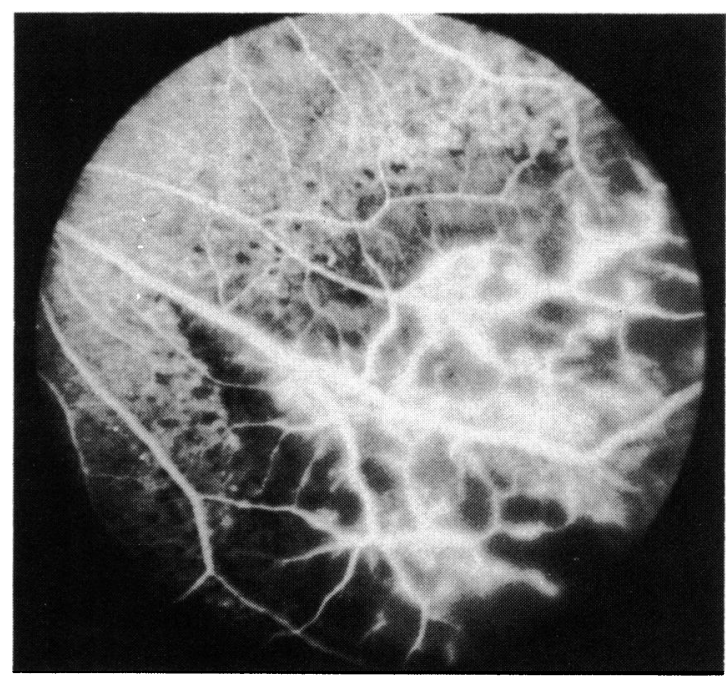

Fig. 9 Fluorescein angiogram of right eye, patient 2, in late phase. There is marked retinal vascular leakage with evidence of involvement of the retina at all levels. No choroidal pattern is visible in the involved area. 
of $\mathrm{T}$ cell numbers and function revealed only $5 \% \mathrm{~T}$ cells in the peripheral blood (normal 60-80\%) and an abnormal response to mitogen stimulation with concanavalin-A and staphylococcal proteins (Dr Gillian Sheppard, New York Hospital, New York, NY). Oral and esophageal candidiasis persisted requiring treatment with amphotericin $B$. Interstitial pneumonia was diagnosed. Bronchoscopy revealed numerous $\mathrm{CMV}$ inclusions, and routine cultures grew Haemophilus, parainfluenzae and pneumococcus. Broad spectrum antibiotics (cefamandole and Bactrim (sulphamethoxazole and trimethoprim)) were initiated; the patient remained febrile. Two weeks after admission the fundus OD showed enlargement of the inferonasal area of retinal infiltration with a more prominent haemorrhagic component. The left eye showed minimal enlargement of the lesions previously described. Within 2 weeks a massively haemorrhagic area of retinitis was noted OD and the left eye appeared similar to the right, with large areas of retinal infiltration and only a few haemorrhages. No vitreous haze was noted. The fovea of both eyes were spared, but it was impossible to test visual acuity.

The patient underwent exploratory laporotomy and splenectomy on 30 June 1981 because of suspicion of an occult lymphoma. Histopathological examination of lymph nodes and spleen revealed CMV inclusions. Sputum culture at this time, as well as culture of the biopsied lymph nodes and spleen, grew $\mathrm{Myco}$ bacterium avium intracellulare. All stains for acid-fast bacteria (AFB) of the sputum and excised tissues were negative. The patient remained unreactive to purified protein derivative (PPD) of intermediate and high strengths, as well as to candida, trichophyton, and mumps. The CMV complement fixation titre was $1: 64$, and CMV (ELISA) IgG titres had fallen from 1:128 to 1:32 (Dr Donald Armstrong, MemorialSloan Kettering Cancer Center, New York, NY). CMV ELISA IgM titres (indicative of acute infection) were undetectable. Multiple urine and sputum cultures for CMV were negative. The right fundus showed large confluent patches of haemorrhagic retinitis in many areas still in a perivascular distribution and sparing fixation. The lesions OS also increased in size and became more haemorrhagic. The appearance of both eyes was now the classic tomato sauce ('catsup') and crumbled cheese appearance of CMV retinitis. Four days later the patient expired.

General pathology. A general post-mortem examination performed days later revealed disseminated cytomegalic inclusion disease of the lungs, colon, spleen, lymph nodes, liver, and adrenals. Viral cultures were negative. There were no lesions in the brain.
Ocular pathology. A posterior segment of the right eye only was removed for histopathological study. Examination revealed extensive areas of fullthickness necrosis of the retina and retinal pigment epithelium (Fig. 10). Massively enlarged cells with intranuclear and intracytoplasmic inclusions were noted (Figs. 11A, B).

Indirect immunoperoxidase localisation of cytomegalovirus proteins was done on paraffin sections of the eye with antibody to cytomegalovirus (Northeastern Biomedical Laboratories, Inc.) absorbed with uninfected cells of the cell line in which the virus was grown. (Detailed methods for the purification and characterisation of this antibody and the staining procedure will be reported elsewhere.) Numerous cells in all layers of the retina and occasional pigmented epithelial cells contained reaction product, often in the absence of abnormality (Fig. 12A). An adjacent control section stained with preimmune IgG shows only endogenous peroxidase activity within choroidal vessels and black pigment in epithelial cells and chromatophores (Fig. 12B).

\section{Discussion}

Cytomegalovirus (CMV) is a species-specific DNA virus characterised by a bizarre 'cytomegalic' effect on host cells. ${ }^{12}$ Human cytomegalovirus is a herpes virus (as are herpes simplex, varicella-zoster, and Epstein-Barr viruses) morphologically characterised by a capsid composed of 162 elongated hexagonal prisms (capsomers) enveloped by a bilaminar membrane probably derived from the host cell nucleus. ${ }^{1213}$ Once infected, the host cell synthesises viral particles and produces the pathognomonic 'owl's eye' intranuclear and multiple intracytoplasmic inclusions and a swollen cytoplasm. ${ }^{12}$ Although the herpesviruses cannot be distinguished from each other ultrastructurally, the cytopathic effect and inclusions produced by CMV are so distinctive that it can be used to distinguish CMV from other members of the herpesvirus family. ${ }^{12}$

Serological studies indicate that previous infection has occurred in about $80-90 \%$ of middle-aged adults. ${ }^{14}$ Acute infection may be accompanied by an elevation of serum IgM antibodies for CMV. ${ }^{15}$ Complement fixing antibodies, when present, demonstrate the existence of prior infection with the virus, though they may fall to undetectable levels with time. ${ }^{16} \mathrm{This}$ observation may indicate that the incidence of prior infection with CMV is even higher than previous studies suggest. ${ }^{16}$ Most authorities believe that once infected, the host carries the CMV genome and possibly viral particles for a lifetime, though the exact storage sites remain unknown. ${ }^{14}$ The clinician may diagnose active CMV infection by an increase in 
complement fixation antibodies, culture of blood or a lesion, or biopsy confirmation of the classic histopathological picture. ${ }^{6}$ Excretion of the virus in the urine, saliva, semen, and from the uterine cervix is widespread $^{17}$ and does not necessarily indicate active disease, but viraemia probably does and correlates best with clinical findings in immunosuppressed patients. ${ }^{141819}$ Virus has been isolated from tears of patients with and without retinitis and does not appear to correlate with ocular involvement. ${ }^{20}$ In patients with retinitis cultures of subretinal fluid and vitreous may be positive. ${ }^{351621}$ In patients with panuveitis aqueous taps have yielded live virus. ${ }^{1516}$ Serological studies, however, may have certain pitfalls, as in one of our patients and in previously reported cases, ${ }^{3}$ where complement fixing antibodies may not rise. Alternatively immunohaemagglutination of immunofluorescent titres may confirm infection. ${ }^{14}$ It has also been noted that a fall in complement fixing titres in the presence of active infection signifies a poor prognosis. ${ }^{14}$

Active cytomegalic inclusion disease (CID) may be broadly divided into congenital and acquired infection. Congenital infection classically occurs in premature infants and is associated with microcephaly, hepatosplenomegaly, thrombocytopenia, purpura, and periventricular calcifications. Chorioretinitis and its sequelae, deafness and intellectual dysfunction, may be observed if the infant survives. ${ }^{14}$ The congenital retinitis is often associated with optic atrophy. The disease is probably acquired transplacentally and at times may be devoid of clinical manifestations. Indeed one-third of infants dying of unrelated causes show classical CMV inclusions in the salivary glands. ${ }^{13}$

Acquired CID infection in adults may affect the central nervous system, retina, reticuloendothelial system, kidneys, adrenals, and lungs. ${ }^{13}$ The acquired disease in adults usually occurs in one of 3 clinically different manners: (1) in immunosuppressed patients, (2) following multiple blood transfusions (postperfusion syndrome), and (3) in an infectiousmononucleosis-like or infectious hepatitis syndrome. In immunosuppressed patients CID is manifest clinically by viraemia with positive blood cultures, arthralgias, fever, leucopenia, pneumonitis, retinitis, and hepatitis. In healthy individuals it may present as an Epstein-Barr virus-negative mononucleosis syndrome with atypical lymphocytosis. Until recently ocular CID has been reported almost exclusively in patients with well-defined immunodeficiency, such as those with neoplastic disorders of the haemopoietic and reticuloendothelial systems or treatment with immunosuppressive therapy, the most common being renal transplant recipients. ${ }^{1314161922-26}$ Until recently only 2 cases of CID retinitis in normal, healthy adults have been reported. Foerster ${ }^{27}$ described a patient with unilateral uveitis in whom histopathological studies of the eye revealed granulomatous choroiditis and retinal necrosis with typical CMV inclusions. Chawla et al. ${ }^{28}$ described a previously healthy woman with an Epstein-Barr virus-negative mononucleosis-like syndrome who had pinpoint chorioretinal lesions. The diagnosis of CID retinitis was made on the basis of an increase in complement fixing antibodies. No culture on pathological studies was obtained. There was no retinal haemorrhage or coalescence or expansion of the lesions as is usually seen in CID retinitis. ${ }^{22} 2526$

Ocular involvement in CID is predominantly seen in the retina, and the retinitis which may occur is characterised by white intraretinal lesions, often confluent, retinal haemorrhages, microaneurysms, ${ }^{29}$ retinal oedema, attenuated vessels, perivascular sheathing, and exudative detachment. ${ }^{21}$ An optic nerve head mass, ${ }^{30}$ optic atrophy, vitritis, and anterior uveitis are often present. ${ }^{3132}$ Other conditions may mimic the ocular picture of CID and include herpes simplex retinitis, ${ }^{334}$ toxoplasmosis, ${ }^{35}$ Candida sp. (and other fungi), Behçet's syndrome, the syndrome of unilateral or bilateral acute retinal necrosis (ARN or BARN syndrome) $)^{36} 37$ and subacute sclerosing panencephalitis (SSPE). ${ }^{38}$

The association between male homosexuality and acquired sexually transmitted disease is well known. Localised herpes simplex infections, giardiasis, amoebiasis, viral hepatitis, syphilis, and gonorrhoea are endemic among homosexual males and have usually been attributed to venereal transmission and frequent contacts with different partners. A high incidence of cytomegalovirus shedding in urine and semen has been reported in asymptomatic homosexual men, the significance of which is unclear. ${ }^{17}$ Recently reports have appeared linking homosexual males with the development of a severe acquired immunodeficiency manifested by weight loss, fever, and severe, unrelenting, often fatal infection with opportunistic micro-organisms including cytomegalovirus, herpes simplex virus, Pneumocystis carinii, cryptococcosis, and Candida albicans. ${ }^{7811}$ Homosexual males may also develop as part of their spectrum of acquired disease, the 'gay bowel' syndrome ${ }^{9}$ and Kaposi's sarcoma. ${ }^{10}$ A characteristic of the acquired immunodeficiency syndrome is a reversal of the normal T-helper cell to T-suppressor cell ratio, with a profound decrease in the absolute numbers of T-helper cells. " Acute viral infections, especially of the herpesvirus family, including cytomegalovirus $^{39}$ and Epstein-Barr virus, ${ }^{4041}$ have been shown to cause immunosuppression and reversals of the helper/suppressor cell ratio. Although many theories have been proposed to explain the outbreak 
of acquired immunodeficiency-including exposure to drugs, ${ }^{42}$ autoimmunisation due to parenteral exposure to sperm inoculated through colonic abrasions, ${ }^{43}$ and/or infection with either known or as yet unknown transmissible agents-all are at present speculative and need thorough investigation.

The present cases are noteworthy in that both men were exclusively homosexual, presented with a picture of wasting, diarrhoea, and leucopenia, developed oesophageal candidiasis, showed progressive CMV retinitis, and died with disseminated CMV. Of potential clinical significance in case 1 was the ability to make the diagnosis of ocular cytomegalic inclusion disease ante mortem by means of virus isolation from a vitreous tap. Although antiviral therapy in this patient was unsuccessful, it is hoped that earlier suspicion and confirmation of the diagnosis in this fashion might improve outcome in future patients. At present, however, the best treatment has not been identified except for the discontinuation of immunosuppressive agents. Limited experiences with transfer factor ${ }^{44}$ and antiviral drugs such as adenine arabinoside, ${ }^{25}$ floxacidine (FIAC), and acyclovir have yielded only rare successes. ${ }^{173133}$ The possible therapeutic role of interferon and immunomodulators will need to be clarified by controlled clinical trials.

We are grateful to Mr Robert Campanile and Mr Bruce Bailey for the photography and to Ms Leona Brin for typing the manuscript.

This work was supported in part by an unrestricted grant from Fight for Sight, Inc., New York, NY, and National Eye Institute Core Grant No. EY 01867.

\section{References}

1 Cangir A. Sullivan MP. The occurrence of cytomegalovirus infections in childhood leukemia. Report of three cases. JAMA 1966; 195: 616-22.

2 Duvall CP. Casazza AR, Grimley PM, et al. Recovery of cytomegalovirus from adults with neoplastic disease. Ann Intern Med 1966; 64: $531-41$.

3 Aaberg TM, Cessarz TJ, Rytell MW. Correlation of virology and clinical course of cytomegalovirus retinitis. Am J Ophthalmol 1972; 74: 407-15.

4 Smith ME. Retinal involvement in adult cytomegalic inclusion disease. Arch Ophthalmol 1964; 72: 44-9.

5 Burns RP. Cytomegalic inclusion disease uveitis. Report of a case with isolation from aqueous humor of the virus in tissue culture. Arch Ophthalmol 1959; 61: 376-87.

6 Smith TF. Cytomegalovirus infections: current diagnostic methods. Mayo Clin Proc 1981: 56: 767.

7 Gottlieb MS, Schroff R, Schanker HM, et al. Pneumocystis carinii pneumonia and mucosal candidiasis in previously healthy homosexual men: evidence of a new acquired cellular immunodeficiency. N Engl J Med 1981; 305: 1425-31.

8 Siegal FP, Lopez C. Hammer GS, et al. Severe acquired immunodeficiency in male homosexuals, manifested by chronic perianal ulcerative herpes simplex lesions. N Engl J Med 1981; 305: 1439-44.

9 Phillips SC. Mildvan D, William DC, et al. Sexual transmission of enteric protozoa and helminths in a venereal-disease-clinic population. N Engl J Med 1981; 305: 603-6.
10 CDC-Kaposi's sarcoma and pneumocystis pneumonia among homosexual men-New York City and California. Morbid Mortal Weekly Rep. 3 July 1981: 30(25): 305-7.

11 Mildvan D. Mathur U. Enlow RW. et al. Opportunistic infections and immune deficiency in homosexual men. Ann Intern Med in press.

12 Schwartz JN, Daniels CA, Shivers JC, Klintworth GK. Experimental cytomegalovirus infection. Am J Pathol 1974; 77: $477-92$.

13 Boniuk I. The cytomegaloviruses and the eye. Int Ophthalmol Clin 1972: 12: 169-90.

14 Weinstein L. Fields B. eds. Seminars in infectious diseases. New York: Thieme-Stratton, 1980; 3: 243-64.

15 Berger BB. Weinberg RS, Tessler HA, et al. Bilateral cytomegalovirus panuveitis after high dose corticosteroid therapy. Am J Ophthalmol 1979; 88: 1020-5.

16 Nicholson DH. Cytomegalovirus infection of the retina. Int Ophthalmol Clin 1975; 15: 151-62.

17 Drew WL. Mintz L, Miner RC, et al. Prevalence of cytomegalovirus infection in homosexual men. J Infect Dis 1981; 143: $188-92$.

18 Fiala M, Chatterjee SN, Carson S, et al. Cytomegalovirus retinitis secondary to chronic viremia in phagocytic leukocytes. $A m ~ J$ Ophthalmol 1977; 84: 567-73.

19 Fiala M. Payne JE, Berne TV. Epidemiology of cytomegalovirus infection after transplantation and immunosuppression. $J$ Infect Dis 1975; 132: 421-33.

20 Cox F, Meyer D. Hughes WT. Cytomegalovirus in tears from patients with normal eyes and with acute cytomegalovirus and chorioretinitis. Am J Ophthalmol 1975; 80: 817-24.

21 Broughton WL. Cupples HP. Parver LM. Bilateral retinal detachment following cytomegalovirus retinitis. Arch Ophthalmol 1978; 96: 618-9.

22 Murray HW, Knox DL. Green WR, et al. Cytomegalovirus retinitis in adults, a manifestation of disseminated viral infection. Am J Med 1977; 63: 574-84.

23 Astle JN. Ellis PP. Ocular complications in renal transplant patients. Ann Ophthalmol 1974; 6: 1269-74.

24 Malek GH, Kisken WA. Problems in diagnosis and treatment in renal transplantation. Am J Surg 1970; 119: 334-6.

25 Pollard RB, Egbert PR, Gallagher JG, et al. Cytomegalovirus retinitis in immunosuppressed hosts. I. Natural history and effects of treatment with adenine arabinoside. Ann Intern Med 1980; 93: 655-64.

26 Egbert PR, Pollard RB, Gallagher JG, et al. Cytomegalovirus retinitis in immunosuppressed hosts. II. Ocular manifestations. Ann Intern Med 1980; 93: 664-70.

27 Foerster HW. Pathology of granulomatous uveitis. Surv Ophthalmol 1959; 4: 283-326.

28 Chawla HB, Ford MD, Munro JF, et al. Ocular involvement in cytomegalovirus infection in a previously healthy adult. $\mathrm{Br} \mathrm{Med}$ J 1976; ii: 281-2.

29 Augsburger JJ, Henry RY. Retinal aneurysms in adult cytomegalovirus retinitis. Am J Ophthalmol 1978; 86: 794-7.

30 Marmor MF, Egbert PR, Egbert BM, et al. Optic nerve head involvement with cytomegalovirus in an adult with lymphoma. Arch Ophthalmol 1978; 96: 1252-4.

31 Chumbley LC, Robertson DM. Smith TF, et al. Adult cytomegalovirus inclusion retino-uveitis. Am J Ophthalmol 1975; 80: 807-16.

32 deVenecia G. Rhein GM, Pratt MW, et al. Cytomegalic inclusion retinitis in an adult. A clinical, histopathologic, and ultrastructural study. Arch Ophthalmol 1971; 86: 44-57.

33 Cogan DG. Immunosuppression and eye disease. Am J Ophthalmol 1977; 83: 777-88.

34 Minckler DS, Mcleon EB, Shaw CM, et al. Herpes virus hominis encephalitis and retinitis. Arch Ophthalmol 1976; 94: 89-95.

35 Friedmann CT, Knox DL. Variations in recent active toxoplasmosis. Arch Ophthalmol 1969; 81: 481-93. 
36 Young SJA, Bird AC. Bilateral acute retinal necrosis. $\mathrm{Br} \mathrm{J}$ Ophthalmol 1978; 62: 581-90.

37 Price Jr FW, Schlaegel Jr TJ. Bilateral acute retinal necrosis. Am J Ophthalmol 1980;89: 419-24.

38 Nelson DA, Weiner A, Yanoff $M$, et al. Retinal lesions in subacute sclerosing panencephalitis. Arch Ophthalmol 1970; 84: 613-21.

39 Rinaldo CR Jr, Carney WP, Richter BS, et al. Mechanisms of immunosuppression in cytomegalovirus mononucleosis. $J$ Infect Dis 1980; 141: 488-95.

40 Reinherz EL, O'Brien C, Rosenthal P, et al. The cellular basis for viral-induced immunodeficiency: analysis by monoclonal antibodies. J Immunol 1980; 125: 1269-74.
41 De Waele M, Thielemans C, Van Camp BKG. Characterization of immunoregulatory $\mathrm{T}$ cells in EBV-induced infectious mononucleosis by monoclonal antibodies. $N$ Engl J Med 1981; 304: 460-2.

42 Durack DT. Opportunistic infections and Kaposi's sarcoma in homosexual men. $N$ Engl J Med 1981; 305: 1465-7.

43 Hurtenbach U. Shearer GM. Germ cell-induced immune suppression in mice: Effect of inoculation of syngeneic spermatozoa on cell-mediated immune responses. J Exp Med in press.

44 Keith CG, Lanauze J. Cytomegalovirus retinitis. Med J Aust $1980 ;$ i: $24-6$. 